\title{
An uncommon cause of unexplained nonbloody diarrhea: When mind knows eyes may see
}

\author{
Hemanta Kumar Nayak, Abhai Verma, Uday Chand Ghoshal, Rakesh Pandey ${ }^{1}$ \\ Departments of Gastroenterology and ${ }^{1}$ Pathology, Sanjay Gandhi Postgraduate Institute of Medical Sciences, Lucknow, Uttar Pradesh, India
}

$\begin{array}{ll}\text { Abstract } & \begin{array}{l}\text { Collagenous colitis (CC) is characterized by chronic secretory diarrhea with the apparently } \\ \text { normal gross appearance of the colonic mucosa. A biopsy is usually diagnostic. The symptoms } \\ \text { of CC appear most commonly in the elderly. In CC, the major microscopic characteristic is a } \\ \text { thickened collagen layer beneath the colonic mucosa. The reported case represents unexplained } \\ \text { nonbloody diarrhea of a systemic lupus erythematosus patient, on extensive evaluation found } \\ \text { to have CC. This case highlights the importance of considering a rare possibility of CC as a } \\ \text { differential in a patient of unexplained nonbloody diarrhea. }\end{array} \\ \text { Key words } & \begin{array}{l}\text { Collagen colitis, microscopic colitis, nonbloody diarrhea } \\ \text { Kand }\end{array}\end{array}$

\section{Introduction}

Collagenous colitis (CC) is a relatively rare condition that is diagnosed when a patient with chronic watery nonbloody diarrhea has an endoscopically or radiographically normal colon; however, colonic mucosal biopsies show unique inflammatory changes. Because the mucosa is not ulcerated or otherwise disrupted, diarrhea generally does not contain blood or pus. CC primarily affects the colon, but the terminal ileum can also be involved. Patients undergoing either sigmoidoscopy or colonoscopy for unexplained diarrhea who have normal endoscopic findings should have biopsy samples taken to diagnose or rule out either form of microscopic colitis.

\section{Case Report}

A middle-aged female with systemic lupus erythematosus presented with a recurrent passage of loose, watery stools of 6-month duration. She had five to six stools per day of

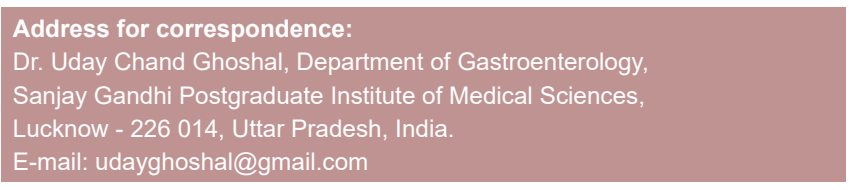

\begin{tabular}{|l|c|}
\hline \multicolumn{2}{|c|}{ Access this article online } \\
\hline \multirow{2}{*}{$\begin{array}{l}\text { Website: } \\
\text { www.jdeonline.in }\end{array}$} & Quick Response Code \\
\hline $\begin{array}{l}\text { DOI: } \\
\text { 10.4103/0976-5042.193743 }\end{array}$ & \\
\hline
\end{tabular}

watery, nonmucoid, and nonbloody nature not associated with vomiting, abdominal pain, or cramps. There was no weight loss or history of passage of undigested food particles, and there was no pedal edema. There was also no history of joint pains and swelling or use of nonsteroidal anti-inflammatory drugs. Physical examination did not reveal any abnormality except for malar rash.

Stool examination did not reveal ova, cyst, or parasite on microscopy and enteropathogen on culture. Hematological parameters including erythrocyte sedimentation rate, liver function tests, lipid profile, and serum electrolytes, urea, and creatinine levels were within normal range with the exception of thrombocytopenia. Serological test for human immunodeficiency virus was nonreactive. Colonoscopy did not reveal any abnormality [Figure 1a]; multiple biopsies from colonic mucosa was obtained, which revealed maintained crypt architecture, increased thickness of subepithelial collagen plate [10-12 $\mu \mathrm{m}$; black arrowhead in Figure 1b] and focal increase in intraepithelial lymphocytes (16-18/100 epithelial cells); these findings were consistent with (CC). There was also a few entrapped capillaries in collagen plate as shown in Figure 1c (yellow arrow) and thick

This is an open access article distributed under the terms of the Creative Commons Attribution-NonCommercial-ShareAlike 3.0 License, which allows others to remix, tweak, and build upon the work non-commercially, as long as the author is credited and the new creations are licensed under the identical terms.

For reprints contact: reprints@medknow.com

How to cite this article: Nayak HK, Verma A, Ghoshal UC, Pandey R. An uncommon cause of unexplained nonbloody diarrhea: When mind knows eyes may see. J Dig Endosc 2016;7:118-9. 


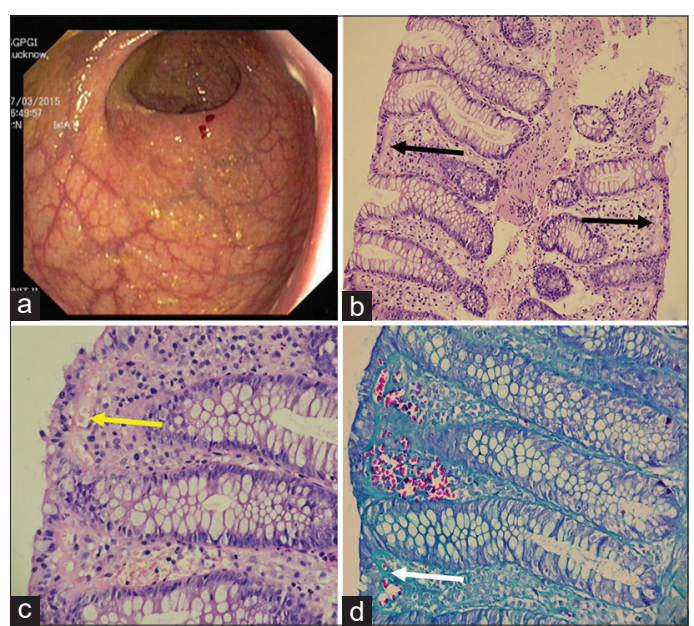

Figure 1: (a) Colonoscopy showing normal colonic mucosa with its vascular pattern, (b) ascending colonic mucosal biopsy showing thickened sub-epithelial collagenous band stained with hemotoxylin and eosin stain (black arrow) consistent with collagenous colitis, (c) a few entrapped capillaries in collagen plate are shown (yellow arrow), (d) thick sub-epithelial collagen band stained with Masson Trichrome stain (white arrow)

sub-epithelial collagen band stained with Masson Trichrome stain [Figure 1d, white arrow]. She responded well to treatment with azathioprine and 5-amino salicylate.

\section{Discussion}

CC belong to the group of microscopic colitis, a term which was first introduced by Read et al. in 1980. ${ }^{[1,2]}$ Collagen colitis is a relatively rare conditions diagnosed when a patient with chronic, watery, and nonbloody diarrhea has an endoscopically or radiographically normal colon, but colonic biopsies show unique thick subepithelial collagen band. ${ }^{[3]}$ Because the mucosa is not ulcerated or otherwise disrupted, diarrhea generally does not contain blood or pus. Our patient presented with the classical features of CC which include recurrent nonbloody, nonmucoid diarrhea without any abdominal pain and weight loss.

Endoscopy with biopsy is essential to establish the diagnosis. Colonoscopy generally reveals normal mucosal appearance. Collagen colitis has characteristic thickened subepithelial collagen band which is more than $10 \mu \mathrm{m}$ in thickness. ${ }^{[4]}$
Sulfasalazine, mesalamine, bismuth subsalicylate, cholestyramine, loperamide, and diphenoxylate hydrochloride, and atropine sulfate have all been used with variable results in treating CC. ${ }^{[5]}$ Steroids have also been tried in cases where the regular drugs do not give desired relief. Methotrexate and azathioprine are usually reserved for the few cases who do not respond to steroids or any of the above mentioned drugs. ${ }^{[6]}$ Our patient responded well to 5-aminosalicylate and azathioprine. It usually runs a benign course, and most of the patients achieve symptomatic and histopathologic resolution within months of treatment.

\section{Conclusion}

This clinical entity should be kept in mind in any patient with unexplained watery diarrhea with normal colonoscopy and biopsy should be taken even from normal colonic mucosa. Based on symptom severity and disease duration, a step-wise approach to treatment is suggested. ${ }^{[7]}$

\section{Financial support and sponsorship Nil.}

\section{Conflicts of interest}

There are no conflict of interest.

\section{References}

1. Ingle SB, Patle Y, Kediya A, Gadgil P. Collagenous colitis: Cause of unexplained diarrhea. Biomedicine 2012;32:279-80.

2. Read NW, Krejs GJ, Read MG, Santa Ana CA, Morawski SG, Fordtran JS. Chronic diarrhea of unknown origin. Gastroenterology 1980;78:264-71.

3. Agnarsdottir M, Gunnlaugsson O, Orvar KB, Cariglia N, Birgisson S, Bjornsson S, et al. Collagenous and lymphocytic colitis in Iceland. Dig Dis Sci 2002;47:1122-8.

4. Sylwestrowicz T, Kelly JK, Hwang WS, Shaffer EA. Collagenous colitis and microscopic colitis: The watery diarrhea-colitis syndrome. Am J Gastroenterol 1989;84:763-8.

5. Calabrese C, Fabbri A, Areni A, Zahlane D, Scialpi C, Di Febo G. Mesalazine with or without cholestyramine in the treatment of microscopic colitis: Randomized controlled trial. J Gastroenterol Hepatol 2007;22:809-14.

6. Pardi DS, Loftus EV Jr., Tremaine WJ, Sandborn WJ. Treatment of refractory microscopic colitis with azathioprine and 6-mercaptopurine. Gastroenterology 2001;120:1483-4.

7. Bohr J, Tysk C, Eriksson S, Abrahamsson H, Järnerot G. Collagenous colitis: A retrospective study of clinical presentation and treatment in 163 patients. Gut 1996;39:846-51. 